\title{
Modelos pedagógicos y formación de profesionales en el área de la salud
}

\section{Pedagogical models and the formation of healthcare professionals}

\author{
Análida Elizabeth Pinilla • Bogotá, D.C. (Colombia)
}

\section{Resumen}

Introducción: la formación de profesionales en salud tiene fundamento pedagógico y epistemológico para dar servicio al paciente y la comunidad.

Objetivos: presentar un análisis de las relaciones entre las competencias profesionales por desarrollar y la formación de profesionales en el área de la salud. Exponer el concepto de modelos pedagógicos, los lineamientos de la formación profesional, particularmente en especialidades médicas, mediante la relación docencia-servicio y el aprendizaje basado en problemas.

Métodos: investigación documental, búsqueda de literatura científica publicada en español e inglés, en las bases de datos como Medline, Redalyc, SciELO, Google, Universidad Nacional de Colombia, centros de referencia y libros mediante las palabras clave.

Resultados: se conceptualiza la formación por competencias de profesionales en las ciencias de la salud, se detallan las competencias de profesionales genéricas o transversales y específicas; los alcances y las limitaciones actuales de la formación y se exponen cuatro experiencias de formación basada en competencias.

Conclusiones: la formación de profesionales en ciencias de la salud debe conducir a la graduación de profesionales autónomos y críticos con profesionalismo que en su práctica demuestren competencias profesionales transversales y específicas; éstas se evalúan permanentemente en la relación con cada paciente; para alcanzar lo anterior es indispensable la formación pedagógica de docentes y la concienciación de directivos y entes gubernamentales. Los currículos tienen un componente nuclear y otro flexible que permiten el desarrollo de las potencialidades de cada estudiante por medio del método del aprendizaje basado en problemas con casos clínicos en la relación docencia-servicio y en equipo interdisciplinario. (Acta Med Colomb 2011; 36: 204-218)

Palabras clave: aprendizaje, salud, competencias, competencias profesionales, modelo pedagógico, educación basada en competencias, universidad.

\footnotetext{
Abstract

Introduction: the formation of health professionals has pedagogical and epistemological background to serve the patient and the community.

Objectives: to present an analysis of the relationship between professional competences to develop and professional formation in the area of health. Discuss the concept of pedagogical models; guidelines for professional formation, particularly in the medical specialties, through teaching-service relationship and problems-based learning.

Methods: systematic search of published literature in Spanish and English in databases such as Medline, SciELO, Google, Universidad Nacional de Colombia, reference centers, and books with the keywords.

Results: was conceptualized the formation of professional competences in the area of health, detailing the generic or transversal and specific professional competences, the scope and limitations of current formation and four experience of competency-based education.

Conclusions: the professionals formation in health sciences should lead to the graduation of autonomous and critical professional with professionalism in their practice and they should demonstrate specific and transversal professional competences; which are continually assessed the relationship
}

Dra. Análida Elizabeth Pinilla Roa: Internista. Diabetóloga. MSc. en Educación Superior con Énfasis en Docencia Universitaria. Especialista en Evaluación y Construcción de Indicadores de Gestión para la Educación Superior. Candidata al Doctorado en Educación. Profesora Asociada. Facultad de Medicina. Universidad Nacional de Colombia. Miembro Grupo de Apoyo Pedagógico y Formación Docente. Bogotá, D.C. (Colombia)

Correspondencia: Dra. Análida Elizabeth Pinilla Roa. Bogotá, D.C. (Colombia)

E-mail: aepinillar@unal.edu.co

Recibido: 01/VIII/2011 Aceptado10/X/2011 
with each patient to achieve this is essential pedagogical formation of professors and consciousness of directors and government. The curricula have a nuclear and a flexible component that allows the development of the potentialities of each student by the method of problem-based learning with clinical cases in the relationship teaching-service and interdisciplinary team. (Acta Med Colomb 2011; 36: 204-218)

Keywords: learning, health, competences, professional competences, pedagogical model, competency-based education, university.

\section{Introducción}

El objetivo de esta investigación documental es presentar un análisis de las relaciones entre las competencias y la formación de profesionales en el área de la salud. Para comenzar se expone el concepto de modelos pedagógicos con su referente epistemológico, los lineamientos de la formación profesional desglosados en programas de pregrado, la relación docencia-servicio, el aprendizaje basado en problemas y los programas de posgrado en particular las especialidades médicas con las competencias profesionales por desarrollar.

Después, se conceptualiza acerca de la formación por competencias de profesionales en ciencias de la salud. A continuación, se exponen las competencias profesionales que se dividen en genéricas o transversales a diversas profesiones y las específicas de cada profesión. En seguida, se exponen algunos alcances y limitaciones en la formación actual de profesionales y se termina con la recopilación y análisis de cuatro experiencias de carácter internacional y nacional de formación basada en competencias. Se dejan planteadas unas reflexiones finales.

\section{Material y métodos}

Investigación documental en educación universitaria y en salud. Se hizo la búsqueda de la literatura científica publicada en español e inglés, en las bases de datos como Medline, Redalyc, SciELO, Google, Universidad Nacional de Colombia, centros de referencia y libros mediante las palabras clave; se revisaron libros colombianos, latinoamericanos y europeos en español afines con el tema. Para la selección se revisaron los títulos y resúmenes de documentos, proyectos y artículos originales. Una vez recopilados se inició la clasificación y organización de acuerdo con el tema principal, los subtemas, la cronología y la estructura del proyecto. Luego, se inició una lectura interpretativa y un análisis crítico para ordenar y sintetizar los avances relacionados con los modelos pedagógicos, lineamientos de la formación profesional, relación docencia-servicio, aprendizaje basado en problemas, competencias profesionales en ciencias de la salud e investigaciones curriculares basadas en competencias.

\section{Resultados}

\section{Modelos pedagógicos y referentes epistemológicos}

Para comprender cómo se define la formación de un profesional es esencial precisar qué es un modelo pedagógico; la palabra modelo significa un "esquema teórico [...] de un sistema o de una realidad compleja [...] para facilitar su comprensión", según la Real Academia de la Lengua Española (1). Entonces, un modelo pedagógico es una "herramienta conceptual" que recopila una serie de relaciones para describir un sistema complejo de la educación en el aula (Flórez, 1999) (2); es la representación de las relaciones que predominan en los actos de enseñar, de aprender y de evaluar, en las características de la relación maestro- alumno, en la concepción que tenga el profesor de aprendizaje, de evaluación y en consecuencia cómo evalúa.

Como sinónimo de modelo pedagógico está teoría pedagógica o enfoque pedagógico. Un modelo pedagógico define un conjunto de atributos que caracterizan el proceso de la educación y formación "que se construye y orienta según un método históricamente determinado por una concepción del hombre, la sociedad y el conocimiento" (Claret, 2003,p.16) (3), por consiguiente da cuenta de: ¿El qué, los contenidos? ¿El para qué, la intencionalidad? ¿El cómo, la metodología y las técnicas de enseñanza y aprendizaje? ¿El cuándo, los momentos? ¿A quién? ¿Con qué medios? ¿Con qué tipo de relación docente-discente? ¿Con cuál concepto de evaluación? Por tanto, un modelo pedagógico "es la representación de las relaciones que predominan en la escuela entre profesor y alumno (Flórez, 1999; Sáenz, 2002) (2,4). En este sentido, un modelo pedagógico se expresa en un código educativo como el "conjunto de principios estructurales y regulativos" (Moreno, 2003, p.17) (5).

Los dos modelos pedagógicos desarrollados que más se contrastan son el positivista y el constructivista; cada uno, tiene su propia epistemología de la ciencia y el conocimiento, de igual forma del currículo, la enseñanza, la evaluación y el aprendizaje.

Vale precisar que lo usual en ciencias de la salud ha sido el modelo tradicional positivista en particular en el ciclo básico de las ciencias básicas. Para el ciclo de formación clínica desde el pregrado y la formación de posgrados se ha desarrollado igualmente con un modelo tradicional positivista que desde siempre se ha desenvuelto en la atención al paciente en la relación de docencia-servicio llamada originalmente docencia-asistencia (Ministerio de la Protección Social, Acuerdo 003 de 2004) (6); es decir, el estudiante se forma en la práctica profesional con los pacientes bajo la tutoría de los profesores que, a su vez, son médicos especialistas. En los dos ciclos básico y clínico se ha iniciado un viraje hacia un modelo pedagógico constructivista, en algunos casos es mínimo y en otros es mayor de acuerdo con la postura epistemológica y la formación como educador de cada médico-docente. 
En el aula la relación del profesor con el estudiante se desarrolla según el modelo pedagógico del profesor, las acciones se desenvuelven en torno al conocimiento científico desde la mirada del estudiante y la del profesor para construir un conocimiento escolar. Por tanto se desarrolla un modelo didáctico con "los principios para orientar, realizar e interpretar las actividades de orden general y de orden particular [...] en el aula de clases. Las actividades generales son las referentes a los procesos de enseñanza, aprendizaje y evaluación (Claret, 2003, p.15) (3).

\section{Lineamientos de la formación profesional 2.1 Programas de pregrado con modelo pedagógico tradicional}

En el modelo pedagógico tradicional flexneriano con epistemología positivista, la formación de profesionales en salud en el pregrado se ha caracterizado por la formación inicial en el ciclo básico, centrado en contenidos, en el cual el estudiante cursa diversas asignaturas de las ciencias básicas (por ejemplo: biofísica, bioquímica, fisiología, histología, microbiología, morfología, parasitología, entre otras); luego, se desarrolla el ciclo de las asignaturas clínicas desde la semiología, las asignaturas por grupo etarios y las principales ramas de la medicina (cirugía general, medicina interna, pediatría, obstetricia y ginecología).

Este modelo o enfoque pedagógico tradicional es transmisionista porque se considera que el profesor es el que sabe y el alumno adopta el papel de receptor pasivo, se enfatiza en los contenidos recopilados por la ciencia. Aquí el enfoque de la evaluación del estudiante es terminal o por resultados, con "preguntas objetivas" (Flórez, 1999) (2).

Esta modalidad de educación por asignaturas y contenidos, en el ciclo básico, "prioriza los conceptos abstractos sobre los ejemplos concretos" (Morales y Landa, 2004, p. 3) (7), ha estado centrado en las decisiones del profesor, con predominio de clases expositivas. Para exponer este modelo tradicional clásico, Perrenoud (2010) explica que "el modelo clínico lleva a cabo una inversión en el modelo clásico, según el cual la teoría precede a la acción" (p.107) (8); en este enfoque se ha venido realzando la acumulación de datos y temas con un aprendizaje memorístico o repetitivo, la evaluación se ha centrado en "comprobar la memorización de contenidos y hechos" (Morales y Landa, 2004, p. 3) (7) y se ha dejado de lado el desarrollo de habilidades procedimentales, de formación de valores, de pensamiento crítico y de la formación para actitudes de profesionalismo (Pinilla, Rojas, Parra, 2009; Zabala y Arnau, 2008) $(9,10)$. Por tanto, se ha considerado que el profesor es un transmisor de conocimiento y el estudiante es un receptor pasivo que memoriza para pasar el examen.

A este respecto, el desarrollo de asignaturas desmembradas lleva al estudiante a no comprender por qué son importantes ciertos conocimientos de las ciencias básicas, de modo que al llegar a las asignaturas del área clínica, donde comienza a elaborar historias clínicas en interacción directa con los pacientes, el estudiante siente que no aprendió "casi nada" y que ahora sí comprende que es lo significativo de los diversos temas y cómo los debe integrar para analizar y crear la solución de los problemas que presenta un paciente determinado. En palabras de Venturelli (2003) "la metodología actual de cátedras aisladas y sin conexión alguna con las demás imposibilita una práctica integradora continua que armonice las ciencias básicas con las ciencias de los ámbitos clínicos, socioeconómicos...” (p. 7). Por fortuna, desde los años ochenta la Organización Mundial de la Salud (OMS) propuso nuevos enfoques para la formación de profesionales de la salud con "innovación educacional que centra el proceso en el estudiante [...] y usa los problemas prioritarios como base educacional" (Venturelli, 2003, p. 2) (11).

La formación profesional en medicina se divide en el ciclo de las ciencias básicas, desintegrado del ciclo de las ciencias clínicas y además se exagera la cantidad de contenidos, currículo tradicional y enciclopedista, con un aprendizaje superficial (con una función reproductiva del aprendizaje, limitado a lo esencial y memorístico que produce dificultades en la apropiación de conceptos (12-14); lo anterior lleva a que el estudiante al afrontar pacientes en el ciclo de semestres clínicos, presente problemas para el desarrollo de competencias profesionales $(15,16)$. En otras palabras, el estudiante en el primer ciclo de formación se centra en los aspectos cognitivos y en el segundo ciclo su formación va de la mano con la atención al paciente, lo cual le facilita el desarrollo de competencias profesionales al integrar conocimientos, habilidades y actitudes.

En la Tabla 1 se esquematiza el modelo pedagógico tradicional, denominado enciclopedista por asignaturas o agregado, que se ha utilizado en el área de la salud, y se deja la reflexión de cómo sería un modelo pedagógico activo, constructivista basado en el desarrollo de competencias. En el primer modelo se prioriza la cantidad de contenidos, se considera el conocimiento acabado, por esto el estudiante comprende que debe memorizarlo, y su formación se basa en

Tabla. 1. Aspectos y características del modelo pedagógico tradicional.

\begin{tabular}{|l|l|}
\hline \multicolumn{1}{|c|}{ Aspectos } & \multicolumn{1}{c|}{ Características } \\
\hline Prioriza & Contenidos, enciclopedista. \\
\hline Conocimiento & Acabado, autores clásicos. \\
\hline Enfoque del aprendizaje & $\begin{array}{l}\text { Memorístico, superficial (Marton y Saljö, } \\
1976) \text { con heteroestructuración (Not, 1994). }\end{array}$ \\
\hline Fuente del conocimiento & Sólo el profesor y los textos. \\
\hline Papel del alumno & Receptor pasivo. \\
\hline Estrategias didácticas (metodología) & Clase magistral, expositiva, transmisionista. \\
\hline Relación maestro-alumno & Vertical, autoritaria, centrada en lo cognitivo. \\
\hline Tipo de equipo de trabajo & Multidisciplinar. \\
\hline Tipo de aprendizajes & $\begin{array}{l}\text { El alumno aprende lo que el maestro dice, } \\
\text { selecciona y al ritmo que éste impone. }\end{array}$ \\
\hline $\begin{array}{l}\text { Concepto de evaluación } \\
\text { (Rendimiento académico) }\end{array}$ & $\begin{array}{l}\text { Cuantitativa, hace énfasis en la medición } \\
\text { final, para certificar; el maestro decide si el } \\
\text { estudiante repite y se evalúa sólo contenidos } \\
\text { impartidos por el profesor. }\end{array}$ \\
\hline Fuente original: Pinilla-Roa AE.
\end{tabular}


la heteroestructuración (el estudiante se forma por la acción del profesor, como agente externo) (Not, 1994) (17) y con un aprendizaje superficial $(13,14)$.

Según Marton y Saljö $(1976)(13,14)$, el aprendizaje puede ser superficial y profundo. El superficial es mecánico o repetitivo de cierta información que se reproduce para el profesor o para el examen. En contraste, el aprendizaje profundo ocurre cuando el estudiante se interesa, toma la "tarea como un medio para su enriquecimiento personal" [...], relaciona los componentes de la tarea entre sí y con otras materias, integrándolas en un conjunto" (Hernández, et ál., 2005,p.17) (12) y busca establecer relaciones entre el nuevo conocimiento y el previo para comprender, es un aprendizaje significativo relacionado con el contexto y que liga la teoría con la práctica "con mejores resultados" (González, 2010, p.15) (18). En la práctica, el estudiante adopta un enfoque cambiante de aprender de acuerdo con el contexto y a las estrategias de enseñanza-aprendizaje-evaluación de cada profesor (12).

En este modelo pedagógico tradicional, la fuente del conocimiento es el profesor porque el alumno es el que no sabe y su función es de receptor pasivo, que asiste a clases magistrales; de tal suerte que los temas son propuestos de forma exclusiva por el profesor expositor; la evaluación es entendida como una acción terminal, el profesor considera que evaluar es dar una “calificación”, con una visión de la evaluación sumativa o terminal del aprendizaje de los estudiantes por medio de un solo instrumento, las pruebas de opciones múltiples con selección única, en donde lo relevante es la técnica para hacer preguntas "objetivas", en la cual se constata si el alumno aprendió lo que le enseñó su profesor, como un conocimiento que ya está culminado, aquí lo que importa para el alumno es memorizar o repetir lo que se le ha dicho en la clase magistral. En este modelo el evaluador emplea la evaluación como herramienta de poder, lo que condiciona al alumno a actuar y argumentar siguiendo el pensamiento del profesor, con ausencia de diálogo en una relación unilateral y vertical, en la cual el docente no puede ser evaluado ni contra argumentado (19-21).

De esta forma, este modelo pedagógico tradicional y positivista refleja las concepciones del profesor acerca de la enseñanza, el aprendizaje, la ciencia, la investigación y la evaluación. A su vez, el estudiante sigue estudiando para satisfacer al docente y pasar el examen más que para su desarrollo profesional $(11,22)$. Por todo lo anterior, se invita a docentes y estudiantes a reflexionar acerca de las posibles consecuencias que ha tenido este modelo pedagógico.

\subsection{Relación docencia-servicio y el aprendizaje basado en problemas}

Por lo anterior, en la década de los años sesenta, un grupo de médicos maestros de la Universidad McMaster (Canadá) reconoció que era necesario modificar la enseñanza de la medicina por contenidos, de corte positivista, por el método de Aprendizaje Basado en Problemas (ABP) de corte constructivista para alcanzar una mejor formación para la práctica profesional. Lo anterior, por la producción desmesurada de conocimiento científico y de los avances de la tecnología lo cual produce un cambio continuo en las competencias profesionales que debe evidenciar un profesional. Este modelo de formación médica fue seguido por la Universidad de Maastricht (Holanda) y la Universidad de Newcastle (Australia) en la década de los años setenta (7) y luego por otras como las Universidades de Ginebra y de Lausana en Suiza. Se ha propuesto que desde el primer semestre se emplee el método de la resolución de problemas, incluso se han suspendido las asignaturas usuales por disciplinas y desde el inicio se le presentan al estudiante situaciones-problema que debe resolver con la ayuda del equipo interdisciplinario de maestros (de las áreas de ciencias básicas y de las clínicas) y de diversas fuentes de información (Perrenoud, 2010) (8).

En el área de la salud la formación profesional desde el pregrado en el ciclo clínico hasta el posgrado en las especialidades médicas y quirúrgicas se ha venido utilizando el método del ABP, de forma empírica y poco definida, desde mediados del siglo XX hasta la actualidad. Se desarrolla un proceso de análisis reflexivo del estudiante para dar soluciones a cada paciente (caso clínico), lo que le facilita el desarrollo del juicio clínico como una parte de las competencias profesionales (genéricas y específicas) que se ampliarán más adelante.

Desde las universidades se firman convenios de docenciaservicio con las instituciones prestadoras de servicios de salud de diverso orden (municipal, departamental, nacional e internacional) para realizar asistencia profesional a los pacientes y realizar la formación de los estudiantes, talento humano competente. Lo anterior, se regula por medio de la relación docencia-servicio para los programas de formación de talento humano del área de la salud, como lo expone el Decreto 2376 del Ministerio de la Protección Social (2010) (23).

Como lo escribió Pinilla (1999), cada caso clínico sale de la vida real en la práctica clínica, en diferentes niveles de atención (primer a cuarto nivel, con graduación progresiva de complejidad) (24). Asimismo, a cada profesor quien es un médico especialista, es el médico-tratante y responsable de un grupo de pacientes, en diferentes escenarios o servicios (consulta externa, hospitalización, urgencias, cuidado intermedio, cuidado intensivo); éste tiene en forma simultánea un grupo de estudiantes de diferente nivel de formación (por ejemplo: asignatura de medicina interna, interno rotatorio, estudiantes de posgrado o residentes de diferentes año I, II o III).

El equipo constituido por el profesor y los estudiantes mencionados es un equipo de trabajo colaborativo, con autonomía y compromiso ético, para brindar atención a cada paciente, esto significa que al estudiante de pregrado y posgrado se le asigna un paciente para que lo asista. Entonces, para crear soluciones a los problemas del paciente, participan en el equipo el profesor y los estudiantes en las revistas docentes; se parte de la elaboración de la historia 
clínica de cada paciente por el estudiante y a partir de los problemas de cada caso clínico se usa un método de indagación, reflexión, análisis y planteamiento de soluciones para cada paciente basadas en el conocimiento médico y la revisión de la literatura. Es pertinente precisar que un problema, en el enfoque pedagógico, es como lo afirman Jessup y Castellanos. "Es una situación enigmática, espontánea o prevista" para la cual no se tiene una "respuesta adecuada y eficaz inmediata", hecho que si bien "produce incertidumbre" se convierte en una "potencialidad, en tanto moviliza una conducta tendiente a la búsqueda de solución [...]. Su carácter está determinado por su formulación y por las etapas que implica el proceso de resolución" (p.147) (25).

El ABP tiene una perspectiva socioconstructivista del aprendizaje, es un método centrado en el estudiante que favorece: la comprensión, la cooperación, el trabajo en equipo, la interacción y el trabajo libre o independiente del estudiante quien motivado repasa, analiza, analoga con situaciones problema similares. Como estrategias alternas, el caso clínico puede ser presentado en forma directa in vivo al borde de la cama; llevarse el caso a una discusión académica en un aula o discusión virtual (Tabla 2).

"Es fundamental aclarar que el caso en cuestión obviamente tiene problemas, es decir plantea interrogantes por resolver. Dentro de esta estrategia existen múltiples modalidades a saber: entrega previa del caso para estudio y discusión posterior en grupo pequeño o en un auditorio más grande; el grupo pequeño favorece la mayor participación y es más útil para el estudiante de menor grado de formación (Pinilla, 1999, p. 108) (24).

Un problema implica una situación intelectual compleja sin solución inmediata, que produce indecisión implica un proceso de análisis, indagación y creatividad para llegar a una resolución (25). Es relativo o diferente en cada grupo, según el área de conocimiento y el nivel de formación. Se sugiere plantear y seleccionar el número y el tipo de problemas según la programación, la asignatura y la disponibilidad de tiempo. En medicina clínica se emplea a diario como método de aprendizaje basado en los casos clínicos que tienen diversa complejidad e incluso conducen a plantear preguntas de investigación, en especial cuando el docente reflexivo va sistematizando una serie de casos con una patología específica. En resumen, el ABP favorece el aprendizaje significativo y profundo para el desarrollo de competencias clínicas y de cuidado del paciente, competencias de comunicación; además, se puede avanzar hacia el desarrollo de competencias de investigación formativa, en las líneas de profundización e investigación $(26,27)$.

Además, otro aspecto es analizar que el desarrollo de competencias por el estudiante va cambiando de acuerdo con cada caso clínico, a pesar de tener los mismos diagnósticos, pero con las particularidades de cada paciente que se plasman en la historia clínica individualizada. Esto significa solucionar los problemas en el contexto, es decir, cada
Tabla 2. Características del aprendizaje basado en problemas.

\begin{tabular}{l} 
Implica procesos de: \\
- Exploración del entorno. \\
- Reconocimiento de la situación problema del caso. \\
- Integración de las ciencias básicas y las clínicas. \\
- Lectura crítica de la literatura relacionada. \\
- Reestructuración de concepciones previas. \\
- Trabajo en equipo colaborativo. \\
- Desartesis de posibles respuestas. \\
\hline Fuente original: Pinilla-Roa AE.
\end{tabular}

situación particular requiere competencias profesionales transversales y específicas (28).

En resumen, el estudiante del área de la salud se forma en la práctica profesional mediante la relación docenciaservicio $(6,23)$.

\subsection{Programas de posgrado}

Desde la creación de las especialidades médico-quirúrgicas en Colombia, hacia finales de los años cincuenta, la formación del residente se hacía en el hospital con la atención directa a los pacientes y bajo la tutoría de los médicos-profesores, es decir, bajo la figura de docenciaservicio. Inicialmente, los médicos se dedicaban al ejercicio de cierta área de la medicina en un hospital de acuerdo con los intereses particulares. Así, Velásquez et ál. informaron que en los programas se iniciaron directamente en el sitio de práctica y sólo años después, o incluso décadas, el programa se vinculó oficialmente a una universidad para avalarlos; los especialistas egresados en esas circunstancias fueron certificados por Ascofame (29).

El docente de posgrado en ciencias de la salud, y en particular en las especialidades médicas, algunas veces de forma empírica, desarrolla un modelo constructivista cuando favorece la construcción y reelaboración del conocimiento por el residente basado en la asistencia y la docencia sobre los casos clínicos, de esta forma el profesional en formación desarrolla competencias profesionales (30).

Los programas de las especialidades médicoquirúrgicas en Colombia corresponden a maestrías según el Decreto 1279 de 2002, artículo 6 (31). En éstas continúa la formación de profesionales de la salud, centrada en la atención de pacientes con patologías que requieren atención médica o clínica y quirúrgica. En medicina existen otros posgrados como maestrías en ciencias básicas (bioquímica, fisiología, morfología, farmacología, etc.) y salud pública, además de los doctorados en ciencias básicas, que están comenzando a desarrollarse en Colombia.

En las especialidades médicas y quirúrgicas se realiza la formación del futuro especialista. A este estudiante de 
posgrado se le denomina residente, es un médico general que comienza sus estudios en una especialidad médica. Estos programas de residencia se realizan en escenarios reales de atención a pacientes en los centros de diferente nivel de atención (primer a cuarto nivel de complejidad) según la Secretaría de Salud de Bogotá (32). Los residentes suelen ser jóvenes o adultos jóvenes, lo que implica un grado importante de autonomía para "tomar las riendas de su formación" (Ricarte y Martínez-Carretero, 2007, p. 108) (33), el residente se desempeña como el médico de los pacientes bajo la tutoría del médico-especialista-profesor.

La formación en posgrado está centrada en el estudiante. Las estrategias didácticas usadas, de forma tradicional y empírica, aplican el método del $\mathrm{ABP}$ que para efectos concretos surge de los problemas reales, médicos o quirúrgicos, por los que consulta un paciente o que el médico le diagnostica.

Por tanto, un estudiante de ciencias de la salud desde el ciclo clínico en el pregrado y luego como residente (estudiante de posgrado de especialidades médicas y quirúrgicas) desarrolla competencias profesionales en el mundo académico, el cual integra la educación universitaria con el mundo laboral del trabajo y la sociedad, puesto que la formación del estudiante se realiza con pacientes, mediante la relación docencia-servicio, en instituciones prestadoras de salud. En consecuencia, este futuro profesional especializado debe poseer las competencias profesionales que abarcan el conjunto de conocimientos (saber), habilidades (saber hacer, procedimientos) y actitudes (saber ser) para el desempeño efectivo en situaciones problemáticas específicas cambiantes y vinculadas a su profesión, que no son soluciones modelo o fórmulas predeterminadas; es claro, que un profesional para seguir siendo competente requiere estar en permanente actualización, por esto debe aprender a aprender, a desaprender y volver a aprender (34-37).

2.3.1 Formación en especialidades y competencias profesionales por desarrollar. En primer lugar, es evidente que el número de residentes que continúa su proceso de formación en este tipo de posgrado es reducido con relación a los grupos en pregrado, por lo cual la tutoría es personalizada con una relación docente-discente más horizontal, centrada en el estudiante, que hace las veces de médico tratante guiado por el profesor-tutor, de modo que el aprendizaje es progresivamente más autónomo.

Cada médico especialista-docente tiene asignado un grupo de pacientes que, a su vez es del médico-residente. Así, el trabajo docente-discente se desenvuelve en el escenario docencia-servicio; en otras palabras, el equipo de trabajo comparte los pacientes y el trabajo que se deriva de la atención a cada enfermo. En la práctica, el residente elabora cada historia clínica, organiza el diagnóstico y los planes de diagnóstico y tratamiento para presentarlos y discutirlos con el docente, día a día, en la llamada revista docente. En esta estrategia didáctica, el equipo conformado por el docentemédico-especialista y los estudiantes, de pregrado y posgrado, revisan a cada paciente para definir el diagnóstico, los exámenes necesarios para estudiarlo y el tratamiento. En este conjunto de acciones, el residente desempeña actividades asistenciales o de servicio al paciente de la mano del tutor $\mathrm{y}$, poco a poco, va desarrollando competencias profesionales de diferente categoría y va adquiriendo más responsabilidad.

Desarrollar competencias profesionales involucra avanzar y apropiar, cada vez más, los tres elementos clave de una competencia; el profesional-residente los conjuga para actuar: los conocimientos (dimensión cognitiva, saber, conceptos), las habilidades (que pueden ser mentales y procedimentales, dimensión motora, saber hacer, hacer sabiendo o entendiendo lo que se hace) y las actitudes según los valores o virtudes (dimensión afectiva, saber ser).

En este proceso de formación, el docente emplea estrategias didácticas, como revisión de caso clínico, talleres (para aprender haciendo) al revisar casos clínicos similares o para aprendizaje de interpretación de pruebas diagnósticas, por ejemplo radiología, electrocardiografía, gases arteriales, entre otras; sin embargo, la más empleada en el día a día es la revista docente, que consiste en la revisión de pacientes en los diferentes servicios (urgencias, consulta externa, hospitalización, unidades de cuidado intermedio y unidades de cuidado intensivo). Así se desarrolla el método del ABP, con la reflexión de cada caso clínico, con los diferentes problemas y posibles soluciones; este método se despliega por medio de la indagación, el planteamiento de preguntas, la búsqueda de información, la lectura crítica de la bibliografía, el estudio y la aplicación de guías clínicas para facilitar una atención efectiva (pautas organizadas sistemáticamente para asistir las decisiones de los profesionales en salud y los pacientes, con el fin de mejorar el cuidado y fortalecer la posición del paciente en el proceso de su atención) (38). Además, se precisa que este tipo de estrategias didácticas se aplican en centros de diferente nivel de atención (32).

Como afirman Ricarte y Martínez-Carretero (2007) (33):

[...] la formación en posgrado es el momento crucial para "el desarrollo de competencias clínicas más allá de la mera adquisición de conocimientos [...] se considera una formación para adquirir no sólo conocimientos, sino también las habilidades y los valores para el pleno desarrollo de cada especialidad concreta a través de una práctica programada y supervisada (p. 104).

En efecto, la formación de médicos en las especialidades médicas y quirúrgicas, sólo en algunos momentos, se está realizando por medio de un modelo pedagógico constructivista, con aprendizaje profundo centrado en el estudiante de acuerdo con los problemas planteados por los pacientes; se corre el riesgo de continuar con modelos pedagógicos de tipo tradicional y conductista, como parte del currículo oculto, a pesar de las reformas académicas en diversas universidades.

Como se resume en la Tabla 3, en este modelo pedagógico basado en competencias se seleccionan o jerarquizan los contenidos, el maestro comprende que la clave es guiar para que el estudiante aprenda a pensar, a aprender; para que 
Tabla 3. Aspectos y características del modelo pedagógico basado en competencias.

\begin{tabular}{|c|c|}
\hline Aspectos & Características \\
\hline Jerarquiza & Contenidos \\
\hline Meta & $\begin{array}{l}\text { Desarrollo personal, aprender a pensar, aprender a } \\
\text { aprender }\end{array}$ \\
\hline Enfoque del aprendizaje & Profundo, significativo para la comprensión, \\
\hline Enfoque del conocimiento & En construcción y renovación permanente \\
\hline Fuentes de conocimiento & Docente, alumno, textos \\
\hline Papel del alumno & $\begin{array}{l}\text { Activo, autónomo, participativo, agente de inda- } \\
\text { gación e investigación }\end{array}$ \\
\hline $\begin{array}{l}\text { Estrategias didácticas } \\
\text { (metodología) }\end{array}$ & $\begin{array}{l}\text { Acorde a estructuras cognitivas del estudiante. } \\
\text { El profesor coordina el plan con los intereses del } \\
\text { estudiante, se basa en problemas que relacionan el } \\
\text { conocimiento científico con el cotidiano. }\end{array}$ \\
\hline Relación maestro-alumno & $\begin{array}{l}\text { Horizontal, bidireccional, en equipo colaborativo } \\
\text { para construir conocimiento por proceso participa- } \\
\text { tivo }\end{array}$ \\
\hline Tipo de equipo de trabajo & Interdisciplinar y transdisciplinar \\
\hline Tipo de aprendizajes & $\begin{array}{l}\text { Aprendizaje significativo, el alumno aprende con } \\
\text { sentido, asocia lo nuevo con lo que ya sabe, aprende } \\
\text { lo que le motiva y propone al profesor temas y } \\
\text { preguntas a resolver }\end{array}$ \\
\hline Concepto de evaluación & $\begin{array}{l}\text { Proceso permanente; abarca la evaluación diagnós- } \\
\text { tica, formativa y terminal para evaluar el grado de } \\
\text { desarrollo de competencias profesionales }\end{array}$ \\
\hline Fuente original: Pinilla- & \\
\hline
\end{tabular}

aprenda de acuerdo con sus potencialidades e intereses; por tanto se hace partícipe de su formación y puede proponer temas a tratar y encontrar dudas o vacíos en el conocimiento. Por esto el aprendizaje puede ser significativo y profundo $(13,14)$, puesto que cada estudiante evoca sus concepciones para relacionarlo con el nuevo conocimiento, a su vez se trabaja sobre problemas que exigen la participación de varias disciplinas; para ampliar el aprendizaje y la construcción de su conocimiento

La relación entre el docente y el alumno tiende a ser horizontal y bidireccional, con igualdad de posibilidades para escuchar y ser escuchado, con una gama de alternativas de acuerdo con la postura epistemológica y el modelo pedagógico del docente; si el docente es constructivista busca "plantear, reproducir, apropiar y aplicar los conceptos científico en el contexto escolar [...], integrar los conceptos previos de los alumnos con los conceptos del profesor en un proceso participativo equilibrado" (Claret, 2003, p. 21) (3). En este mismo enfoque el docente hace la evaluación por procesos, de forma permanente que abarca la evaluación de entrada o diagnóstica, la evaluación formativa que se realiza durante el desarrollo de la asignatura y la evaluación sumativa o terminal, en ésta se debe evaluar no sólo el alumno, sino el profesor, el programa o la institución.

A su vez, ahora, la formación y evaluación de profesionales contempla al estudiante como persona que cada vez va desarrollando competencias en un sentido holístico, pues siente, piensa, sabe y actúa (actitudes y valores, conocimientos y habilidades). De lo expuesto se infiere que en la formación de profesionales en las ciencias de la salud ya se ha venido adelantando, en parte un modelo de educación basada en competencias; sin embargo, se debe reflexionar acerca de cómo optimizarlo, cómo velar por el desarrollo de la gama de competencias profesionales y no quedarse en las de conocimiento médico y procedimentales, sino dar igual relevancia a otras competencias como las de profesionalismo, administración, docencia e investigación. Por esto Schonhaut-Berman et ál (2009) afirman que, al día de hoy, la formación en posgrado "continúa desarrollándose con un enfoque asistencial” (p. 34) (41).

\section{Formación de profesionales con un modelo pedagógico por competencias}

En la Tabla 3 se presentan las características de este modelo pedagógico. Venturelli (2003) denomina innovador al modelo de formación profesional basado en el desarrollo de competencias. Este autor resalta que está basado en el método de resolución de problemas y detalla las características siguientes: este método se puede utilizar con casos clínicos en los diferentes niveles de atención; desde la atención primaria, de tipo promoción de la salud y prevención de la enfermedad, con trabajo en centros de primer nivel en una comunidad, hasta la atención de paciente de segundo, tercer o cuarto nivel de atención, es decir, en hospitales (11).

Se focaliza en el estudiante, quien debe pasar del aprendizaje superficial memorístico y heterónomo hacia el aprendizaje autónomo, profundo con significado, en el que tiene la oportunidad de construir su propio currículo flexible. El docente pasa de ser transmisor de conocimiento a ser el guía, tutor o facilitador.

Se jerarquizan los contenidos de acuerdo con las prioridades en salud decantadas por la epidemiología clínica; además, impone la integración de las ciencias básicas con las clínicas y, por tanto, la creación de equipos interdisciplinarios de profesores universitarios

A las características mencionadas por Venturelli (2003) (11) se pueden adicionar otras como: en este modelo, centrado en el estudiante, es necesario que él desarrolle competencias transversales en tecnología de la información y comunicación; epidemiología clínica; de comunicación con los colegas, el paciente y la familia; además, aprenda a trabajar en equipo.

La presentación y sustentación de cada caso clínico favorece el desarrollo de competencias de comunicación. Vale la pena remontarnos a la formación de profesionales en salud, en diversas universidades con el trabajo y aprendizaje del estudiante en el área clínica, desde pregrado hasta posgrado, basado en los casos clínicos y quirúrgicos que presentan diversidad de problemas por resolver. Cada paciente, con sus situaciones-problema impone la integración de conceptos por medio del trabajo interdisciplinario; así se facilita el desarrollo de habilidades diversas (de raciocinio clínico 
en la atención al paciente, procedimentales para proponer alternativas de diagnóstico y tratamiento) de la mano de las actitudes frente al paciente y su familia.

Es pertinente reconocer que para el desarrollo de competencias profesionales específicas son esenciales las competencias básicas (por ejemplo, lectura, escritura, análisis, síntesis, inferencia, correlación, asociación, argumentación, entre otras) y las competencias profesionales genéricas (por ejemplo, en tecnología de la comunicación e información, relaciones interpersonales, trabajo colaborativo, entre otras) $(40,41)$. Además, el estudiante apoyado en unas y otras continúa avanzando en su desarrollo personal y profesional.

Los profesores de ciencias de la salud, en particular en las asignaturas clínicas, han empleado de forma empírica desde hace décadas el ABP, que favorece el aprendizaje profundo y significativo basado en casos clínicos reales, in vivo, de la vida cotidiana, atendidos por los diferentes profesionales de enfermería, medicina, nutrición, odontología, psicología, terapia física, terapia ocupacional, terapia del lenguaje, trabajo social, entre otras. En palabras de Falcó (2004), el estudiante aprende con "lo que ve y hace en los centros de prácticas, y la propia experimentación-socialización a lo largo de la carrera universitaria [...] para configurar su ideal de competencia profesional" (p. 43) (42).

Así mismo, es necesario que los profesores generen estrategias, para trabajo en grupos pequeños, que favorezcan la interacción entre condiscípulos del mismo nivel y con otros de nivel más avanzado (interno rotatorio, residente), así como con el profesor. Este es el caso de las rotaciones en asignaturas clínicas obligatorias o asignaturas del currículo flexible (líneas de profundización o asignaturas optativas) (27).

Por consiguiente, el profesional en formación desde el pregrado hasta el posgrado debe comprender la necesidad de la educación continua por la magnitud del avance del conocimiento científico (pruebas de diagnóstico, ingeniería genética, farmacología, entre otras) junto al avance tecnológico aplicado en pruebas de laboratorio e imaginología (radiología, resonancia magnética, tomografía axial computadorizada) y la generación continua de equipos para ejecución de procedimientos (por ejemplo: cirugía laparoscópica, hemodinamia, litotripsia, punciones articulares dirigidas por tomografía, entre otras).

Además, si el maestro y el alumno comprenden la importancia de la evaluación sumativa o terminal, la evaluación formativa y la diagnóstica, entonces lo deseable es que lleguen a un acuerdo sobre los criterios y reglas del juego para la evaluación del desarrollo de competencias profesionales.

Según Barrón (2004), esta propuesta de formación profesional basada en el desarrollo de competencias requiere de (43):

- Un currículo flexible que permita la formación polifacética y de autonomía al estudiante para elegir ciertas asignaturas electivas.

- Una formación de docentes para su papel de tutor o asesor dejando el de transmisor de conocimiento o instructor, la finalidad es apoyar al estudiante para que avance en su proyecto de vida, por esto el docente sirve de guía.

- La formación del estudiante en la práctica, lo que permite relacionar el conocimiento académico con el conocimiento profesional; así, el residente se forma en el escenario del trabajo real, de atención a los pacientes y comunidades, por consiguiente se requiere que "los alumnos desarrollen un aprendizaje autónomo y significativo en escenarios reales de trabajo" (Barrón, 2004, p. 33).

- El método del $A B P$, iniciado hacia los años sesenta en medicina, el cual es útil como estrategia de enseñanza-aprendizaje porque confluyen diversas áreas del conocimiento y favorece el trabajo colaborativo en grupo; además, el estudiante, quien es el centro del aprendizaje, adquiere conocimiento pero al mismo tiempo desarrolla habilidades $\mathrm{y}$ actitudes, es decir, competencias profesionales.

\section{Competencias profesionales en ciencias de la salud}

Las ciencias de la salud se dividen en dos grupos las ciencias básicas (disciplinas) y las ciencias clínicas (profesiones). El primero, está constituido por biofísica, bioquímica, farmacología, fisiología, histología, microbiología, morfología, parasitología, entre otras. En el segundo, están bacteriología, enfermería, instrumentación quirúrgica, nutrición, odontología, optometría, terapia (física, ocupacional y del lenguaje), medicina general y todas las especialidades médicas y quirúrgicas, medicina veterinaria, ingeniería de alimentos, entre otras.

A continuación se expone un referente de las competencias profesionales de este grupo de profesionales, como lo plantea Perrenoud (2004) "este inventario no es definitivo, ni exhaustivo" (p. 10), un referencial "no puede garantizar una representación consensuada, completa y estable de una profesión" (p. 10) y mucho menos de un grupo de profesiones (44).

El proyecto Tuning en América Latina (2007), en medicina, insistió en pasar de un currículo tradicional por asignaturas a un currículo basado en competencias, centrado "en el estudiante y con integración de las ciencias básicas y clínicas" (p. 256). En esta profesión, los participantes de este proyecto concluyeron las competencias específicas médicas, que denominaron tradicionales, por ejemplo "la capacidad de redactar la historia clínica" (p. 267). Además, en las conclusiones y sugerencias, plantearon las "competencias emergentes asociadas al desempeño profesional", que corresponden a las competencias genéricas o transversales, entre las cuales están "gestión de servicios de salud, bioética, aspectos legales, informática y comunicación” (16).

\subsection{Competencias profesionales genéricas o transversales}

Las competencias genéricas o transversales se refieren a los conocimientos, habilidades y actitudes generales, 
comunes a diferentes profesiones; por ejemplo: de comunicación (relaciones interpersonales, trabajar en equipo para relacionarse con otros, aprender a hablar en público); el profesionalismo, que incluye virtudes como responsabilidad, adaptabilidad, honestidad, creatividad; competencias tecnológicas; en investigación, entre otras. Por tanto, son un tipo de competencias profesionales que son comunes y esenciales en cualquier profesional de ciencias de la salud.

Baños y Pérez (2005) sustentan que lo tradicional ha sido la formación de profesionales en ciencias de la salud centrada en competencias específicas y han quedado olvidadas las competencias transversales (28):

[...] las competencias específicas y ha obviado

la preocupación por la instauración de ciertas competencias transversales a pesar de ser consideradas como importantes. [...] es evidente que la comunicación escrita es una competencia que debe desarrollarse durante los estudios universitarios, pero la mayoría de los estudiantes de ciencias de la salud tienen pocas posibilidades de hacerlo más allá de algunos trabajos esporádicos (p. 217).

No obstante que las competencias transversales son necesarias para ejercer de forma competente cualquier profesión no se han generado espacios reales en el currículo; es decir, no se programan asignaturas puntuales para su desarrollo (28). El proyecto Tuning en Europa las agrupó en instrumentales (capacidad de análisis y síntesis, comunicación oral y escrita, conocimiento de idiomas, manejo de un ordenador, gestión para buscar información, etc.), interpersonales (trabajo en equipo interdisciplinario, comunicación con expertos de otras áreas, reconocimiento de la diversidad y multiculturalidad, compromiso ético, etc.) y sistémicas (aplicar los conocimientos en la práctica, en investigación, creatividad, liderazgo, trabajo autónomo, diseño y gestión de proyectos, etc.) (28).

A continuación se recopilan las propuestas por diversos autores $(45,46)$.

\subsubsection{Competencias de comunicación}

El profesional en salud debe tener competencias para la comunicación interpersonal con los demás profesionales (el trabajo en equipo para relacionarse armónicamente con otros), con el paciente y la familia. La atención y educación en salud involucra al paciente en el proceso de toma de decisiones; por tanto estos profesionales deben ser competentes para comunicarse con el paciente, la familia y diversos especialistas por medio oral, escrito y electrónico para avanzar en el enfoque de diagnóstico y tratamiento del paciente.

En otras palabras, se dice que todo profesional, en ciencias de la salud, debe realizar una relación profesionalpaciente excelente basada en la comunicación y el respeto, teniendo la virtud de saber escuchar y aceptar al paciente cuando está elaborando su historia clínica. Entonces, según Velásquez et ál., el residente debe desarrollar competencias de comunicación oral, gestual y escrita para su cotidiani- dad; pero también debe saber redactar textos narrativos y científicos para aprender a publicar y aprender a hablar en público (29); además, desarrollar competencias para usar la tecnología de la información y la comunicación (TIC).

\subsubsection{Competencias éticas y profesionalismo}

"La competencia ética es el profesionalismo", se entiende como un conjunto de valores, principios y normas de actuación con las cuales se ha de ejercer una profesión (Escudero, Vallejo y Botías, 2008, p. 19) (47). Se expresa en actitudes como adherencia a los principios de confidencialidad e integridad académicocientífica, altruismo, autonomía, prudencia, responsabilidad, honestidad, creatividad con los pacientes, sensibilidad con todo paciente como parte del juramento hipocrático (sin importar cultura, discapacidad, etnia, género, religión, preferencia sexual, estrato socioeconómico y vinculación política); así mismo, ejercer la medicina de acuerdo con los métodos de la mejor práctica de guías clínicas; conciencia del aprendizaje para toda la vida; respetar a los colegas y estar dispuesto a consultarlos cuando sea necesario.

A este respecto, Cabero (2007) reflexiona sobre la falta de precisión de las metas que debe alcanzar el futuro especialista y si la formación del residente considera fundamental que los intereses de los pacientes estén por encima de los propios; es decir, cuestiona si la formación actual favorece el desarrollo de competencias de profesionalismo que incluyen los principios fundamentales del paciente, esenciales para el ejercicio profesional: la autonomía, el bienestar y la justicia social; en otras palabras, el profesional debe brindar siempre la mejor calidad de atención para reducir el error médico y optimizar el resultado (30).

Como lo exponen Martínez-Carretero y Arnau (2007), el profesionalismo persigue la búsqueda del ejercicio profesional con excelencia para proteger a los pacientes como usuarios del servicio de salud y optimizar las necesidades de salud de la sociedad, acordes con la ética (48). Es decir, todo profesional de las ciencias de la salud debe tener conciencia moral para sus acciones y decisiones frente al paciente, la familia y la sociedad.

\subsubsection{Competencias de gestión y administración}

Frente a la disponibilidad de recursos para atender a la población en salud, el profesional debe ser competente para aplicar estrategias costoefectivas y basadas en la evidencia para la prevención, el diagnóstico y el tratamiento de la enfermedad.

\subsubsection{Competencias pedagógicas y en educación}

En la actualidad las ciencias de la salud han virado hacia la atención primaria para dejar de ejercer una medicina paliativa de prevención secundaria o terciaria; se propone trabajar con la persona sana para educarla en un estilo de vida saludable. Como consecuencia, es necesario repensar la formación profesional con nuevas competencias profe- 
sionales en educación para la intervención oportuna. Para hacer medicina preventiva se debe comenzar a educar el individuo desde la infancia y continuar por toda la vida para que cada quien actúe de modo eficaz para su propio bienestar y el de su familia (49). El profesional en salud debe explicar al paciente y su familia cómo mejorar el estilo de vida (hábitos de actividad física, alimentación, evitar consumo de cigarrillo y alcohol, entre otros); por tanto debe desarrollar competencias como educador; es decir, debe guiar al paciente en este aprendizaje de autocuidado para la prevención y promoción de la salud en los diferentes niveles de atención (50). En resumen, todo profesional en salud tiene una función de educador; por tanto, requiere del desarrollo de estas competencias como parte de su formación integral.

Además, dado el avance desmesurado del conocimiento científico debe ser consciente de su desarrollo profesional continuo; por consiguiente debe ser competente para usar la tecnología, buscar información y estar dispuesto a la actualización permanente por medio de autoaprendizaje y aprender a aprender; por esto, debe asistir en forma continua a seminarios, congresos y cursos especiales de actualización.

\subsubsection{Competencias en investigación}

Todo profesional de salud tiene el compromiso de desarrollar un pensamiento crítico basado en el cuestionamiento y la indagación del conocimiento que aplica a cada paciente, frente a las dudas que le genera resolver cada caso clínico; por esto es esencial crear en el currículo un espacio para que el estudiante apropie los fundamentos de la investigación y la epidemiología clínica.

\subsection{Competencias profesionales específicas}

Las competencias profesionales específicas son capacidades especializadas para realizar tareas concretas propias de una profesión, se aplican en determinado contexto laboral; este sería el caso de la atención a pacientes o la elaboración de estados financieros. Estas competencias específicas comienzan a desarrollarse en el pregrado y luego se van diversificando en la medida en que se avanza en la profesionalización durante la formación posgraduada (Castro, 2006) (51); son necesarias, imprescindibles y evidenciables para el desempeño en determinada profesión; así, cuando un especialista se desempeña con sus competencias profesionales específicas se diferencia de otro; por ejemplo un pediatra de un internista general y éste se diferencia de los subespecialistas de la medicina interna, por ejemplo un cardiólogo.

La formación profesional busca responder a las necesidades que pide la sociedad y el sistema productivo, pero la relación entre la educación universitaria y el mundo profesional puede producir debate en relación con las competencias que se desarrollan en la educación y las que demanda el mundo profesional y su relación con el mundo laboral. Esta posible tensión se expresa cuando se plantea "la competencia laboral desde los escenarios propios del trabajo y la competencia profesional desde el campo de la educación" (Díaz, M., 2006, p. 45) (52). En el caso del área de la salud y, en particular en medicina, desde el pregrado hasta el posgrado se aprende de la realidad profesional y laboral, por medio del ABP en la relación docencia-servicio explicada previamente; además, se trabaja con estrategias didácticas diversas como el método del caso clínico, la discusión, las líneas de profundización $(27,41,53)$.

A continuación se esboza un grupo de competencias profesionales específicas que la literatura considera importantes para el profesional del área de la salud: clínicas o de cuidado del paciente, de conocimiento en salud específico de una profesión que permite diferenciar a los profesionales entre sí $(39,45,46,54)$

\subsubsection{Competencias clínicas para el cuidado del paciente}

Éstas comprenden las diversas acciones que realiza el profesional en la relación con el paciente y su familia, que le permiten generar un enfoque, específico para cada paciente, de prevención, diagnóstico y tratamiento. Éstas son el eje de integración, porque todos los miembros del equipo de salud trabajan alrededor del paciente para aportarle desde su área específica de desempeño profesional (55). Cuando un profesional usa para su desempeño las competencias clínicas requiere integrarlas con ciertas competencias genéricas, por ejemplo, de comunicación, educación y profesionalismo.

El médico general desarrolla competencias profesionales para atender a todos los grupos etarios tanto en las patologías clínicas (pediatría y medicina interna) como quirúrgicas (obstetricia y ginecología y cirugía general). Su competencia es construir una historia clínica con indicadores como motivo de consulta, enfermedad actual, examen físico, selección de exámenes de laboratorio e imágenes diagnósticas, decisión de hipótesis diagnóstica y del plan terapéutico. Además, ejecuta procedimientos diagnósticos y terapéuticos básicos.

Luego el médico especialista va avanzando en el desarrollo de competencias profesionales específicas para brindar servicio a un grupo etario: el pediatra (médico de niños) y el internista (médico de adultos), el cirujano general dedicado a la atención de problemas quirúrgicos de cualquier grupo de edad. Más adelante, se desprenden las subespecialidades por sistemas y órganos; por ejemplo, la medicina interna se subdivide en neurología, cardiología, neumología, nefrología, gastroenterología, reumatología, dermatología, entre otras.

En la medida que un profesional de ciencias de la salud avanza en su formación, va desarrollando competencias profesionales más específicas para brindar, cada vez, una atención más puntual y detallada al paciente. Por ejemplo, un médico general puede formarse como médico internista luego subespecializarse en cardiología y más tarde puede avanzar en una parte, de esta subespecialidad de la medicina interna, al estudiar hemodinamia o arritmología.

\subsubsection{Competencias de conocimiento}

Según la especificidad de cada profesión. A manera de ejemplo, el médico internista se concentra en el desarrollo 
de competencias para atender al paciente adulto, ya sea hospitalizado o ambulatorio; por tanto, debe apropiar un conocimiento amplio y actualizado, que va desde la fisiología, la fisiopatología, la farmacología, la semiología, entre otras, de las enfermedades y aplicarlo en la práctica clínica. Además, principios de epidemiología, bases de la medicina basada en la evidencia y su aplicación en las guías clínicas; así como aprender a buscar literatura médica y hacer una lectura crítica.

En síntesis, un profesional competente es el que ha desarrollado un conjunto de competencias profesionales, en otras palabras, las capacidades profesionales puestas en acción; igualmente, sabe colaborar y aportar en su entorno profesional, en la organización y reorganización del trabajo e incluso transformando el contexto cultural $(34,35,37)$.

\section{Alcances y limitaciones de la formación actual}

En primer lugar, a pesar de la abundante bibliografía sobre el tema de la formación por competencias, falta un largo camino por recorrer en Colombia. Es prioritario superar la tergiversación del término competencia, que algunos docentes y directivos han interpretado como competitividad y otros la han asumido desde una postura positivista de corte conductista y técnico; la postura actual en educación superior universitaria es la del modelo pedagógico constructivista, interpretativo de corte cognitivo. Esto revela cierto desconocimiento de la genealogía de los conceptos competencias en educación y competencias profesionales que se escapa al objetivo de esta investigación documental $(56,57)$.

En segundo lugar, para la apropiación de conceptos, la planeación de currículos por competencias y el desarrollo de éstos se requiere la concienciación de los entes gubernamentales, directivos de las universidades y de la base de los profesores de las universidades; por consiguiente, es necesaria la formación pedagógica de los docentes (39). En consonancia con estos argumentos, Peinado-Herreros (2008) afirma:

Definidas las competencias y el proceso de aprendizaje y evaluación, hay que dejar constancia de que cualquier sistema nuevo no tendrá éxito si no se dispone de un profesorado colaborador dispuesto a llevarlo a cabo. En este sentido, los condicionantes de la metodología docente, así como de los incentivos a los que se enfrente el profesorado para cambiar tradiciones fuertemente arraigadas será fundamental (p. 549) (58).

En tercer lugar, avanzar de un modelo tradicional por asignaturas y contenidos a un modelo por competencias en módulos interdisciplinarios, es algo que está por hacerse. Se requiere la organización de currículos que den prioridad por igual a la formación y la evaluación integral del estudiante, desde el pregrado hasta el posgrado, con todos los atributos que tiene cada competencia: conocimientos, habilidades y actitudes (valores) puestos en acción, es decir, movilizarlos para crear una solución oportuna, inédita a cada situaciónproblema.

\section{Algunas experiencias internacionales y nacionales}

La experiencia internacional es amplia para los currículos en pregrado, que ya están avanzando hacia la formación basada en competencias. Los de posgrados lo hacen apoyándose en la estrategia del caso clínico (mediante el aprendizaje profundo y significativo, el aprendizaje basado en problemas); se resaltan como ejemplos los currículos de la Universidad de Maastricht y MacMaster $(59,60)$. A continuación, a manera de ejemplo, se presentan cuatro investigaciones en esta área.

\subsection{Las competencias profesionales del nutricionista deportivo (Universidad de Barcelona, España)}

Belloto (2006) desarrolló la tesis doctoral "Intervenció Psicopedagogica en la diversitat". (Programa de Doctorado 2001-2003), que tuvo como objetivo principal conocer y desvelar las competencias profesionales del nutricionista deportivo. Para ello, empleó una metodología de investigación sistematizada, de carácter exploratorio y descriptivo. El modelo analítico-conceptual de esta investigación fue cualitativo para intentar "descubrir, captar y comprender una teoría, una explicación y un significado" (p. 109). Se seleccionaron los expertos según su "experiencia profesional, publicaciones en el área y prestigio profesional en el ámbito nacional e internacional" (p. 117). La elaboración de cuestionarios se apoyó en cuatro listados de macrocategorías de competencias: técnicas, metodológicas, participativas y personales (34).

Se realizaron tres rondas. La primera con preguntas abiertas de las cuales se hizo análisis de contenido para "codificarlas adecuadamente, reduciéndolas a categorías" inductivas o emergentes (p. 128). La codificación de forma inductiva, permitió encontrar significados no planeados por el investigador aunque para hacerlo aplicó "todo su bagaje teórico y de experiencias previas" (p. 129). La validez y coherencia interna del análisis de contenido se basó en categorizar "permitiendo que cada categoría sea incluida como un ítem significativo del contenido y excluyente, ya que no permite que un mismo ítem pueda ser colocado en más de una categoría" (p. 136). La fiabilidad se dio por el criterio de saturación o redundancia (cuando la información obtenida comienza a ser repetitiva y redundante).

Para los resultados de la segunda y tercera rondas se hizo análisis cuantitativo "por una escala de valoración de cuatro puntos, a través de métodos estadísticos descriptivos" (p.130); así, se logró establecer el grado de acuerdo entre los expertos sobre cada competencia profesional y cada uno conoció "la tendencia de opinión de los demás expertos del panel (característica de la tercera ronda)" (p. 131).

Se empleó el método Delphi, que consiste en solicitar la participación de expertos, en forma anónima, cada uno emite juicios sobre un tema particular por medio de una serie de cuestionarios, de forma secuencial, diseminados con información resumida y con retroalimentación de opiniones deducidas a partir de las respuestas previas. Es decir, se hace un análisis 
de las opiniones para buscar un consenso, se hacen rondas sucesivas y se termina cuando "las opiniones se estabilizan. Esta forma de proceder ofrece al experto la posibilidad de reflexionar y, en su caso, reconsiderar su postura, debido a la aparición de nuevos planteamientos propios o ajenos" (p. 115).

En el apartado de los resultados de esta investigación, tenemos que se obtuvieron y analizaron las opiniones de 14 expertos (de Australia uno, de Brasil siete, de España tres y de Estados Unidos tres), profesionales que trabajaban en el área en países donde esta profesión presenta diferentes grados de desarrollo. Para esta investigación se utilizó el método Delphi con tres rondas: en la primera, se aplicó un cuestionario de preguntas abiertas (fase exploratoria), donde los sujetos describieron las actividades desarrolladas en su atención a deportistas y personas físicamente activas; la segunda, estuvo compuesta de un listado de competencias profesionales elaborado a partir del análisis de contenido de las respuestas obtenidas en la primera ronda, y se solicitó a los expertos que valorasen las competencias profesionales de este listado por una escala de cuatro grados de valoración. Como resultado se obtuvo un total de 147 competencias profesionales, que fueron clasificadas en cuatro macrocategorías: 38 competencias técnicas, 62 metodológicas, 24 participativas 23 personales. Las competencias profesionales que resultaron tener un menor grado de valoración o de consenso fueron contrastadas con la bibliografía, y algunas de ellas fueron reconsideradas.

Como conclusión se puede afirmar que este trabajo demuestra que el estudio científico (sistemático y riguroso) posibilita un adecuado establecimiento y planificación de los contenidos que deberán componer la disciplina de nutrición deportiva, que empieza a ser incorporada en los planes de estudio de las carreras de nutrición y dietética (34).

\subsection{Competencias transversales en la formación de especialistas en pediatría (Universidad de Chile)}

Schonhaut-Berman et ál. (2009) realizaron una investigación sobre la formación de especialistas en pediatría. El objetivo consistió en identificar las competencias transversales que debe lograr el egresado del programa de formación de especialistas en pediatría de la Universidad de Chile y evaluar su adquisición. La metodología empleada consistió en un estudio cualitativo, descriptivo. Entre noviembre de 2006 y enero de 2007 se seleccionaron informantes clave mediante entrevistas en profundidad: ocho líderes, seis residentes y seis pediatras de la Universidad de Chile, y se les preguntó por la relevancia y el logro de seis competencias transversales. Se utilizó el muestreo intencional, propio del método cualitativo, para buscar los participantes; para determinar el número total de sujetos de la muestra se utilizó el criterio de saturación o redundancia, "el cual se fundamenta en una continua interpelación entre la recogida y el análisis sistemático de datos [...] una vez que se construyen los significados que los participantes ven como su realidad social se deja de preguntar (p. 35). Para garantizar la confiabilidad de los resultados se devolvieron a 5 expertos, 3 de los cuales habían participado, para su revisión y comentarios. Los resultados indican que para enfrentar los actuales desafíos laborales y epidemiológicos, se consideró fundamental la capacitación como médico de cabecera en pediatría ambulatoria y clínica, la adquisición de competencias de urgencia pediátrica y el manejo básico del niño hospitalizado. Se dio relevancia a la incorporación de competencias transversales carentes en el programa de formación de esta especialidad; como bioética, relación médico-paciente-familia, salud pública, trabajo en equipo y medicina basada en la evidencia (MBE). En las conclusiones se afirma que la adquisición de competencias transversales es un desafío para la actual formación del pediatra y su adecuada preparación para el ejercicio profesional.

Se expresa la necesidad de reforzar las competencias en "pediatría ambulatoria, pediatría del desarrollo y urgencias" [...]. Por tanto, las competencias clínicas por sí solas no son suficientes (p. 39), es necesario incorporar nuevas competencias en los programas de formación dado los desafíos actuales. Además, las competencias en docencia y gestión que se requieren para el ejercicio profesional podrían ser asignaturas de libre elección (39).

\subsection{La adquisición de competencias profesionales de medicina familiar comunitaria en Cataluña. Una mirada desde tutores y residentes}

Se trata de una tesis sobre la formación de médicos especialistas en medicina familiar, realizada por Ros (2008). Este trabajo tuvo como objetivo analizar y contrastar las percepciones de tutores y de sus respectivos residentes en la especialidad de Medicina Familiar y Comunitaria sobre las competencias profesionales adquiridas al finalizar la formación de posgrado. La metodología incluyó un estudio descriptivo basado en la estrategia metodológica de la triangulación para visibilizar diferentes facetas, objetivas y subjetivas, de la realidad social objeto de la investigación. Se pretendía contrastar información cualitativa y cuantitativa proporcionada por tutores y residentes. Con un cuestionario conformado por preguntas abiertas y otras con escala cualitativa de valoración; además, grupos de discusión para analizar y clarificar los datos obtenidos en el cuestionario. Primero, usaron un cuestionario para recoger una primera opinión de dos poblaciones: los residentes de tercer año esta especialidad $(\mathrm{N}=240)$ y sus respectivos tutores $(\mathrm{N}=240)$. Después se organizaron grupos de discusión para analizar y clarificar los datos obtenidos en el cuestionario. Este proceso se realizó en paralelo con ambos colectivos.

Los resultados revelan que las competencias más valoradas son las habilidades clínicas básicas, habilidades de manejo, comunicación y preventiva; y las menos valoradas: docencia, investigación y comunitaria, quedando las otras áreas (técnicas instrumentales, aspectos organizativos y familia) en una posición intermedia. Sin embargo, los datos narrativos ofrecen una visión más compleja de la realidad. 
Las conclusiones consideraron que las competencias se consolidan realmente cuando se ponen en práctica y reconocieron el papel del contexto. La formación del especialista continúa dando énfasis en la atención al individuo olvidando un enfoque integral de la salud como son las competencias en atención primaria y medicina preventiva (61).

\subsection{El aprendizaje significativo de la medicina interna a través de la evaluación por competencias clínicas}

Ramírez et ál. (2004) publicaron una investigación sobre las competencias que desarrolla un estudiante de pregrado y posgrado en medicina interna, en la Universidad Industrial de Santander (Colombia). Los objetivos consistieron en implementar una propuesta de evaluación por competencias, que apoyara el aprendizaje significativo de la medicina interna en estudiantes de pregrado y posgrado; se propusieron determinar las competencias clínicas y los indicadores de estas y conocer las concepciones previas de los estudiantes; desarrollar estrategias didácticas que permitieran la construcción de significados conceptuales, procedimentales y actitudinales y evaluar los niveles alcanzados de estas competencias clínicas.

Se recurrió a una metodología de investigación-acción para mejorar la práctica docente; se buscó responder a la naturaleza misma del problema investigado, la evaluación de los estudiantes para apoyar el aprendizaje. Como estrategia de validación se empleó la triangulación con diferentes métodos, "el uso de la triangulación permite establecer relaciones entre diferentes tipos de pruebas, reunir información sobre una misma situación tomada desde diversas fuentes [...], permitiendo señalar los aspectos en que contrastan, confirman o refutan los datos" (p. 112).

Los resultados determinaron las competencias clínicas a desarrollar por estudiantes, internos y residentes: "El estudiante que adquiera la competencia, será evaluado cuando pueda demostrar con desempeños, que tiene el conocimiento científico [...], darle una explicación a su paciente, invitarlo a considerar un cambio en su estilo de vida, etc.; y, por supuesto, lo pueda hacer con demostraciones de seguridad, respeto, sensibilidad y ética (p. 112). En posgrado hicieron auditoría de historias clínicas, evaluación directa para el razonamiento clínico y la resolución de problemas al paciente y un examen teórico-práctico de promoción anual sobre un paciente asignado con anterioridad.

En el apartado de conclusiones se afirma que el proyecto permitió definir las competencias y los indicadores de logro de las mismas, que los estudiantes de pregrado y posgrado, deben construir cuando rotan por el departamento de medicina interna. Además, se logró que los docentes reflexionaran y transformaran el concepto de evaluación, con la implementación de cambios en la metodología para evaluar (62).

\section{Reflexiones finales}

La formación de profesionales en ciencias de la salud debe conducir a la titulación de profesionales autónomos y críticos que en su práctica demuestren competencias profesionales transversales y específicas. Cuando una universidad otorga un título académico está garantizando o avalando la competencia del egresado, que no debería representar un peligro para el paciente, la sociedad o cualquiera de sus miembros.

Para organizar y desarrollar currículos por competencias es indispensable la formación pedagógica de los docentes y la concienciación de directivos y entes gubernamentales. Los programas universitarios de ciencias de la salud deben facilitar a los estudiantes el desarrollo de competencias profesionales, las cuales deben evaluarse de forma permanente en el desempeño con el paciente. En ciencias de la salud se ha trabajado en forma empírica en el desarrollo de competencias de conocimiento y procedimentales pero se debe realzar la formación para el desarrollo de competencias de profesionalismo y, a su vez, optimizar el desarrollo de las que ya se están alcanzando (Ramírez et ál., 2004; Velásquez et ál., 2008) (29,62). En palabras de Toro "para cumplir a cabalidad el papel de médico no basta con tener conocimiento científico para enfrentar la enfermedad; hay que tener conocimientos, la habilidad y la disposición para prestar una ayuda integral al enfermo que sufre" (p.45) (63).

Una reforma académica debe ser de fondo para repensar los currículos como estructuras complejas dinámicas, con un componente nuclear o fundamental y uno flexible para permitir una educación basada en competencias que permita el desarrollo de las potencialidades peculiares de cada estudiante. Se debe permitir al estudiante moverse de acuerdo con sus intereses para alcanzar su proyecto de vida, más aún, en la educación de posgrado.

El método del ABP es adecuado para desarrollar competencias profesionales genéricas y específicas porque cada caso clínico promueve innumerables actividades de tipo análisis y síntesis, razonamiento crítico, búsqueda de información en lengua nativa y segunda lengua, interacción con diferentes profesionales que atienden a un paciente, toma de decisiones cada vez más autónomas según el grado de formación, coordinación de tareas para trabajar en equipo (Baños y Pérez, 2005) (28). En la medida que se aprende con casos clínicos similares, durante las prácticas de aprendizaje mediante la relación docencia-servicio, se va ganando experiencia y, a su vez, se va realizando reflexión sobre la acción de tal forma que surgen preguntas por responder, las cuales originalmente se pueden solucionar por medio de consultas bibliográficas; pero en otras ocasiones llevan a preguntas o problemas que generan proyectos de investigación (Moncada y Pinilla, 2006) (64).

Para concluir, es urgente dejar de pensar en la primacía de los temas y conceptos de cada profesión, de cada asignatura y por tanto de cada profesor, como lo propone Hawes (2005) se debe romper "el tradicional individualismo académico" (p. 38) (65). En otras palabras, se debe evolucionar hacia un trabajo mancomunado entre los maestros de las carreras de las ciencias de la salud, para trabajar los problemas en 
equipos interdisciplinarios que permitan al estudiante el desarrollo de competencias profesionales al aprender a aprender y a desaprender para volver a aprender, es decir, el método de cómo actualizarse de forma permanente y comprender para qué y por qué se aprende algo. El camino para una revolución paradigmática del modelo pedagógico tradicional flexneriano al constructivista para el desarrollo de competencias profesionales en Colombia está por construirse (66).

\section{Agradecimientos}

A la Universidad Nacional de Colombia por la comisión de estudios, al doctor Tiburcio Moreno Olivos, de la Universidad Autónoma del Estado de Hidalgo (México) y a los doctores Fidel Antonio Cárdenas Salgado y Alberto Calderón García de la Universidad Pedagógica Nacional, y al doctor Jaime Casasbuenas Ayala.

\section{Referencias}

1. Real Academia Española (RAE). Disponible en http://www.rae.es.

2. Flórez R. Evaluación pedagógica y cognición. En: Ariza E, editora. Bogotá: McGraw-Hill; 1999.

3. Claret A. Las teorías pedagógicas, los modelos pedagógicos, los modelos disciplinares y los modelos didácticos en la enseñanza y aprendizaje de las ciencias. En Claret A, ed. Educación y Formación del Pensamiento Científico. Cátedra ICFES. Bogotá: Arfo Editores e Impresos Ltda; 2003. p. 21-45.

4. Sáenz ML. Innovación pedagógica y evaluación. En: Madiedo N, Pinilla AE, Sánchez J. eds, Reflexiones en educación universitaria II: Evaluación. Bogotá: El Malpensante S.A; 2002. p. 41-7.

5. Moreno H. Modelos educativos y pedagógicos. En: Moreno, H, compilador. Modelos educativos pedagógicos y didácticos. Bogotá: Editora Géminis; 2003. p. 11-95.

6. Ministerio de la Protección Social, Organización Panamericana de la Salud, Organización Mundial de la Salud. Consejo Nacional para el Desarrollo de los Recursos Humanos en salud. Modelo de evaluación de la relación docenciaservicio. Criterios básicos de calidad para centros de prácticas formativas. Bogotá; 2004. p. 7-12.

7. Morales O, Landa V. Aprendizaje basado en problemas. Theoria 2004; 13: 145 57.

8. Perrenoud $\mathbf{P}$. La construcción de una postura reflexiva a través de un procedimiento clínico. Desarrollar la práctica reflexiva en el oficio de enseñar. $2^{\text {a }}$ reimpresión. Barcelona 2010; P: 103-13.

9. Pinilla AE, Rojas EH, Parra MO. Estrategias de evaluación para fortalecer el aprendizaje. Metasíntesis. Moncada LI, López MC, Sáenz ML, eds. Reflexiones sobre educación universitaria IV: didáctica. Bogotá: Unibiblos; 2009. p. 233-50.

10. Zabala A, Arnau L. El término competencia nace como respuesta a las limitaciones de la enseñanza tradicional. Cómo aprender y enseñar competencias. 11 Colección Ideas Clave. Segunda edición. Barcelona: Editorial Graó, de IRIF, S.L; 2008. p. 19-28.

11. Venturelli J. Modernización de la educación médica: ¿Ilusiones inútiles o necesidad imperiosa?. Venturelli J, ed. Educación Médica. Nuevos enfoques, metas y métodos. Segunda edición, Washington, D.C.: Organización Panamericana de la Salud. Organización Mundial de la Salud; 2003. p. 1-32.

12. Hernández F, Martínez P, Da Fonseca P, y Rubio M. Los enfoques de aprendizaje: una revisión del estado de la cuestión. Aprendizaje, competencias y rendimiento en educación superior. Madrid: La Muralla S.A; 2005. p. 15-49.

13. Marton F, Saljö R. On qualitative differences in learning. I. Outcome and process. British Journal of Educational Psychology 1976; 46: 4-11.

14. Marton F, Saljö R. On qualitative differences in learning. II. Outcome as a function of the learner's conception of the task. British Journal of Educational Psychology 1976; 46: 128-48.

15. Caillon A. Flexibilidad y competencias profesionales en las universidades latinoamericanas. Pedroza, R. compil, Flexibilidad y competencias profesionales en las universidades iberoamericanas. Barcelona, México: Pomares; 2006. p. 178-95.

16. Proyecto Tuning América Latina 2004-2007. Competencias específicas y enfoques de enseñanza, aprendizaje y evaluación. Beneitone P, Esquetini C, González J, Marty M, Siufi G, y Wagenaar R, eds. Reflexiones y perspectivas de la Educación Superior en América Latina. Informe final. España: Universidad de Deusto y Universidad de Groningen. 2007.

17. Not L. Introducción. En Las pedagogías del conocimiento. Primera reimpresión en español. México: Fondo de Cultura Económica Ltda; 1994. p. 7-23.

18. González C. El aprendizaje y el conocimiento académico sobre la enseñanza como claves para mejorar la docencia Universitaria. Calidad en la Educación, 33: $123-46$

19. Cárdenas FA, Ladino Y, Zapata PN. Reflexiones acerca de la evaluación. Claret A, ed. Educación y Formación del Pensamiento Científico. Cátedra ICFES. Bogotá: Arfo Editores e Impresos Ltda; 2003. p. 169-90.

20.Pinilla AE. Evaluación del aprendizaje. En: Encuentro Internacional sobre políticas, investigaciones y experiencias en evaluación educativa: consecuencias para la educación. Universidad Pedagógica Nacional. ICFES. Bogotá. Secretaria General Procesos Editoriales; 2004. p. 276-90.

11. Santos MA. Dime cómo evalúas (en la universidad) y te diré qué tipo de profesional (y de persona) eres. Tendencias Pedagógicas 2004; 9: 89-100.

22. Pinilla AE, Barrera MP, Soto HA, Rojas E, Parra MO, Granados LA. ¿Cómo perciben los estudiantes de pregrado de la Facultad de Medicina de la Universidad Nacional de Colombia su proceso de evaluación académica? Rev Fac Med Univ Nac Colomb 2004; 52: 98 -114.

23. Ministerio de la Protección Social. (2010). Decreto 2376.

24.Pinilla AE. Innovaciones metodológicas. En: Pinilla AE, ed. Reflexiones en Educación Universitaria. Primera edición. Bogotá: Unibiblos; 1999. p. 103 - 17.

25. Jessup MN, Castellanos de Pulido. Problemas como estrategia de educación en ciencias naturales. Claret, A. Educación y Formación del Pensamiento Científico. Cátedra ICFES. Bogotá: Arfo Editores e Impresos Ltda. 2003. p. 137-68.

26. Pinilla AE, López MC. Líneas de Profundización como semillero de investigadores. En: Hernández G, Vargas FA, eds. Experiencias significativas en innovación pedagógica. Bogotá, Unibiblos; 2006. p. 143-55.

27. Pinilla AE. Líneas de profundización. Una propuesta didáctica en búsqueda del desarrollo de competencias. Rev Fac Med Univ Nac Colomb 2008; 5: 370-83.

28. Baños JE y Pérez J. Cómo fomentar las competencias transversales en los estudios de Ciencias de la Salud: una propuesta de actividades. Educación Médica 2005; 8: $216-25$.

29. Velásquez JC, Pinilla AE, Pinzón A, Severiche D, Dennis R. Niño de Arboleda MN. Perfil de formación del posgrado de Medicina Interna en Colombia. Acta Med Colomb. Velásquez JC, Pinilla AE, Pinzón A, Severiche D, Dennis R. Perfil de formación del posgrado de Medicina Interna en Colombia. Acta Med Colomb 2008; 33: 45-57.

30. Cabero L. ¿Cuál es el modelo de especialista que debemos formar? La demanda social frente a la oferta profesional. En: Manual para tutores del MIR. Fundación para la Formación de la Organización Médica Colegial. Madrid: Editorial Médica Panamericana; 2007. p. 23-34

31. Decreto 1279 de junio 19 de 2002. Régimen salarial y prestacional para los docentes de las universidades estatales.

32. Secretaría de Salud de Bogotá. Extraído desde http://www.sdp.gov.co/www/ resources/No\%2021_calidad_serviciosdesalud.pdf.Consultado el 5 de septiembre de 2009.

33. Ricarte JI, y Martínez-Carretero JM. Métodos de enseñanza y aprendizaje del residente. En Manual para tutores del MIR. Fundación para la Formación de la Organización Médica Colegial. Madrid: Editorial Médica Panamericana; 2007. p. 103-14.

34. Belloto ML. Las competencias profesionales del nutricionista deportivo. Tesis de doctorado. Universitat de Lleida. España. 2006. Disponible en: http://www. tesisenxarxa.net/TESIS_UdL/AVAILABLE/TDX-1119106-180209//Tmlb1de1.pdf.

35. Bunk GP. La transmisión de las competencias en la formación y perfeccionamiento profesionales de la RFA. Revista Europea de Formación Profesional 1994; 1: 8-14.

36. Mertens L. Competencia laboral: sistemas, surgimiento y modelos. Montevideo: Cinterfor. 1996

37. Santos J. Modelo pedagógico para el mejoramiento del desempeño pedagógico profesional de los profesores de agronomía de los Institutos Politécnicos Agropecuarios. Tesis de doctorado en Ciencias Pedagógicas. Instituto Superior Pedagógico Enrique José Varona. 2005.

38. Téllez DR, Castillo JS, Reveiz L, Torres M, Gamboa O, Mosquera PA, et ál. Modelos para desarrollar guías de práctica clínica. En: Pardo R, ed. Manual metodológico para la elaboración y adaptación de guías de práctica clínica basadas en la evidencia. Bogotá: Corcas Editores; 2010. p. 3-17.

39. Schonhaut-Berman, Millán-Klusse y Hanne-Altermatt. Competencias transversales en la formación de especialistas en pediatría, Universidad de Chile. Educación Médica 2009; 12: 33-41.

40. Pinilla AE. Las competencias en la educación superior. En: Madiedo N, Pinilla AE, Sánchez J, eds. Reflexiones en educación universitaria II: Evaluación. Primera edición. Bogotá: El Malpensante S.A.; 2002. p. 101-35.

41. Pinilla AE. Innovaciones metodológicas. En: Pinilla AE, Sáenz ML y Vera L. eds Reflexiones sobre Educación Universitaria. Segunda edición. Bogotá: Unibiblos 2003. p. 111-25. 
42. Falcó A. La nueva formación de profesionales: sobre la competencia profesional y la competencia del estudiante de enfermería. Educación Médica; 2004; 7: 42-5.

43. Barrón C. Formación profesional: modelos, perspectivas y orientaciones curriculares. En Barrón, C, Canales, L., Lugo, E., Martínez, L. y Monroy, M., (eds.), Currículum y actores. Diversas miradas, Pensamiento Universitario. Tercera época 97. México, D.F. Centro de Estudios sobre la Universidad; 2004. p. 15-49.

44. Perrenoud P. Diez nuevas competencias para enseñar. Primera edición. Barcelona: Editorial Grao; 2004

45. Epstein RM, Hundert EM. Defining and assessing professional competence. JAMA 2002; 287: 226-35.

46. Palsson R, Kellett J, Lindgren S, Merino J, Semple C, Sereni D. Internal Medicine in Europe. Core competencies of the European internist: A discussion paper. Eur J of Inter Med 2007; 18: 104-108.

47. Escudero JM, Vallejo M, Botías F. El asesoramiento en educación ¿Podrían ser las competencias profesorado una contribución positiva? Revista de Curriculum y Formación de Profesorado 2008; 12: 1-23.

48. Martínez-Carretero JM, Arnau J. Evaluación de la competencia clínica y profesional. En: Manual para tutores del MIR. Fundación para la Formación de la Organización Médica Colegial). Madrid: Editorial Médica Panamericana; 2007. p. $179-90$.

49. Barrera MP. Pinilla AE, Cortés É, Mora G, Rodríguez MN. Síndrome metabólico: una mirada interdisciplinaria. Rev Colomb Cardiol 2008; 15:111-26.

50. Molina DI. Sistema General de Seguridad Social en Salud y ubicación laboral de los médicos internistas en Colombia. En: Hernández C A, Ardila E y Niño de Arboleda MN, eds. La medicina interna en Colombia. Bogotá: Asociación Colombiana de Medicina Interna; 2006. p. 46-79.

51. Castro J. El posgrado y la gestión curricular por competencias profesionales. En: Pedroza R, compil. Flexibilidad y competencias profesionales en la universidades iberoamericanas. Barcelona, España: Ediciones Pomares; 2006. p. 196-210.

52. Díaz M. Introducción al estudio de la competencia, Competencia y educación. En Pedroza R, compil. Flexibilidad y competencias profesionales en la universidades iberoamericanas. Barcelona, España: Ediciones Pomares; 2006. p. 29-58.

53. Becerra F. El aprendizaje basado en problemas: su uso en áreas de ciencias de la salud en la educación superior. Moncada LI, López MC y Sáenz ML, eds. Reflexiones sobre Educación Universitaria IV: Didáctica. Bogotá: Editorial Universidad Nacional de Colombia; 2009. p. 75-86.
54. Wigton RS, Tape TG. Procedural skills for internal medicine. St Louis: Mosby; 1996.

55. Noriega T, Orosa J, Puerta M, Goncalves J, Díaz M, y Pérez-Ojeda J. La competencia clínica como eje integrador de los estudios de pre y post-grado en las Ciencias de la Salud. Revista Facultad de Medicina, 2003; 26: 17-21.

56. Cano ME. La evaluación por competencias en la educación superior, Profesorado Revista de curriculum y formación del profesorado 2008; 12: 1-16.

57. Pinilla AE. Competencias en educación universitaria. Revista electrónica de la Asociación Colombiana para la investigación de educación en Ciencias y Tecnología. Revista Educyt, 2010; 2 (2),

58. Peinado-Herreros JM. Definición de las competencias que debe adquirir e futuro médico. Formación de los profesores. Educación Médica 2008; 11 (Supl. 1): S47-51.

59. Maastricht University. Disponible en: http://www.maastrichtuniversity.nl/. Consultado el 20 de abril de 2011

60. MacMaster University. Disponible en: http://www.mcmaster.ca/. Consultado el 20 de abril de 2011.

61. Ros E. La adquisición de competencias profesionales de medicina familiar comunitaria en Cataluña. Tesis de doctorado. Desde http://www.tdx.cesca.es/ TESIS_UAB/AVAILABLE/TDX-1117104-172753//erm1de1.pdf

62. Ramírez ME, Castellanos-Suárez R, Badillo, R, Naranjo FF, Insuasty JS, Gómez, J, et ál. El aprendizaje significativo de la Medicina Interna a través de la evaluación por competencias clínicas. Investigación-Acción. Revista Salud UIS 2004; 36: 111-24.

63. Toro A. Consideraciones acerca de las cualidades del buen médico y del profesionalismo en medicina. Acta Med Colomb 2011; 36: 45-50.

64. Moncada LI, Pinilla AE. Investigación en educación. Rev Fac Med Univ Nac Colomb 2006; 54: 313-29.

65. Hawes G. Construcción de un perfil profesional. http://www.dqm.usach.cl/doc/ bloques/Edu\%20y\%20Doc/ConstruccionPerfilProfesional.pdf.

66. Carraccio C, Wolfsthal SD, Englander R, Ferentz K, Martin C. Shifting Paradigms: From Flexner to Competencies. Academic Medicine 2002; 77: 361-7.

67. Pinzón CE. Los grandes paradigmas de la educación médica en Latinoamérica. Acta Med Colomb 2008; 33: 33-41. 